\title{
Certain Rheological Aspects of Functionalized Guar Gum
}

\author{
Meenu Kapoor, ${ }^{1}$ Dhriti Khandal, ${ }^{1}$ Ruchi Gupta, ${ }^{1}$ Pinklesh Arora, ${ }^{1}$ Geetha Seshadri, ${ }^{1}$ \\ Saroj Aggarwal, ${ }^{1}$ and Rakesh Kumar Khandal ${ }^{2}$ \\ ${ }^{1}$ Shriram Institute of Technology, Gautum Buddh Technical University, I.E.T. Campus, Sitapur Road, Lucknow 226021 , India \\ ${ }^{2}$ Gautum Buddh Technical University, I.E.T. Campus, Sitapur Road, Lucknow 226 021, India
}

Correspondence should be addressed to Rakesh Kumar Khandal; dr.r.k.khandal@gmail.com

Received 16 January 2013; Accepted 6 March 2013

Academic Editor: R. J. Linhardt

Copyright (C) 2013 Meenu Kapoor et al. This is an open access article distributed under the Creative Commons Attribution License, which permits unrestricted use, distribution, and reproduction in any medium, provided the original work is properly cited.

\begin{abstract}
Guar gum and its derivatives are highly important industrial hydrocolloids as they find applications in various industrial sectors. Guar is a polymer of high molecular weight and its aqueous solutions exhibit unique rheological properties, which has led to its wide acceptance by the industry. In certain industrial applications low molecular weight guar and its derivatives are needed, and conventionally chemical depolymerisation of guar is carried out for this purpose. Radiation processing is a novel and green technology for carrying out depolymerization and can be an ideal substitute for chemical depolymerisation technique. In order to study the effect of radiation on guar derivatives, three types of derivatives have been taken in the present study: carboxymethyl, hydroxyethyl, and methyl guar. The effect of 1-50 KGy radiation dose on the rheological behavior of these derivatives has been studied, and the results have been described in the present paper. The effect on storage and loss modulus with respect to frequency and effect on viscosity with respect to shear rate have been discussed in detail.
\end{abstract}

\section{Introduction}

Guar gum is a polygalactomannan found in the endosperm of the seeds of the plant Cyamopsis tetragonolobus. It is a hydrophilic heteropolysaccharide of mannose and galactose monomer units where the mannose forms the main linear chain of the polymer and the galactose forms the pendant branches. The mannose units are linked together by $\beta$ 1,4 glycosidic bonds and the galactose units are linked to mannose through $\alpha-1,6$ glycosidic bonds [1]. The mannose to galactose ratio of guar gum has been reported to be approximately $2: 1$. Thus, every second mannose unit bears a branch of galactose unit.

Guar gum is a high molecular weight polysaccharide (generally more than 2 million $\mathrm{g} / \mathrm{mol}$ ) that can form extensive intermolecular $\mathrm{H}$-bonding resulting in high solvation and thereby increased viscosity [2]. These attributes of guar gum find it varied applications in the industry [3-11]. Guar gum functions as a thickener, emulsion stabilizer, gelling agent, film former, or texture modifier.

Despite the unique rheological behavior there are certain limitations of guar gum which need to be overcome to ensure its effective use. The excessive hydrophilicity of guar gum along with the high molecular mass prevents complete or homogeneous solvation or hydration of the polymer. The resulting two-phase aqueous solution has certain regions showing increased viscosity and other regions showing the solid phase of undissolved guar gum. The other drawback of guar gum is the low thermal and shear stability, as observed in other natural polysaccharides, which reduces the durability and imposes temperature and heat conditions for its effective performance.

In order to overcome the disadvantages of guar gum, its modification is carried out mainly by the functionalization of the hydroxyl groups present on guar backbone. Various functionalities can be introduced on guar by carrying out etherification of guar with different reagents as shown in Table 1 .

Another aspect of guar gum is its high molecular weight, which may not be always desirable. In several industrial applications, low molecular weight guar is used, which is conventionally produced by degradation of native guar by following chemical route. A novel method for degradation of guar can be radiation processing technology. A comparison 
TABLE 1: Etherification reactions of guar.

\begin{tabular}{lcc}
\hline S. no. & Reaction & Reagent \\
\hline 1 & Carboxymethylation & Monochloroacetic acid \\
2 & Cationization & Quaternary ammonium salts \\
3 & Methylation & Methyl chloride \\
4 & Hydroxyethyl/propylation & Ethylene/propylene oxide \\
\hline
\end{tabular}

of the methodology followed for the degradation of guar by conventional route and by radiation processing is given in Figure 1.

The most important property of guar gum is its unique rheology, which makes it an invaluable industrial product. The rheological behavior of guar has been a subject for study for scientists world over. Venkataiah and Mahadevan [12] investigated the aqueous solutions of guar gum as well as its nonionic hydroxypropyl and anionic carboxymethyl derivatives for their flow properties in the range of low to moderately high shear rates and observed the transition from Newtonian fluid to pseudoplastic fluid. Wientjes et al. [13] studied the linear viscoelastic behavior of guar gum solutions as a function of frequency, temperature, polymer concentration and molecular weight and revealed the importance of different relaxation mechanisms. Aubry and Moan [14] focused on the rheological effect of hydrophobically modified hydroxypropyl guar gum and demonstrated that the linear and nonlinear rheological behaviors of such associating systems were dependent on the nature, concentration, and distribution along the chain of hydrophobic junctions. Zhang et al. [15] have studied the semidilute solutions of hydroxypropyl guar gum (HPGG) with respect to their viscosity changes under various HPGG concentrations added salts and temperatures could be well described by the Cross viscosity model.

In the present paper, the effect of irradiation on guar and its carboxymethyl, hydroxypropyl, and methyl derivatives has been studied in respect to the change in the rheological behavior.

\section{Materials and Methods}

The methodology followed for studying the effect of radiation processing on guar and its derivatives involved the following steps.

2.1. Guar Gum and Derivatives. The sample of guar gum was procured from a local supplier. The carboxymethyl, hydroxypropyl, and methyl derivatives of D.S./M.S. 0.1 and 0.2 were synthesized by well-established techniques as published previously $[16,17]$.

2.2. Irradiation of Samples. Guar gum and its derivatives (hydroxypropyl, carboxymethyl, and methyl of DS 0.1 and 0.2 ) were sealed in plastic bottles, which were packed in a cardboard box. The box was then irradiated at different doses $(1,2.5,5,10,20$, and $50 \mathrm{KGy})$ at the Co-60 gamma irradiation facility available within the institute. All specimens were

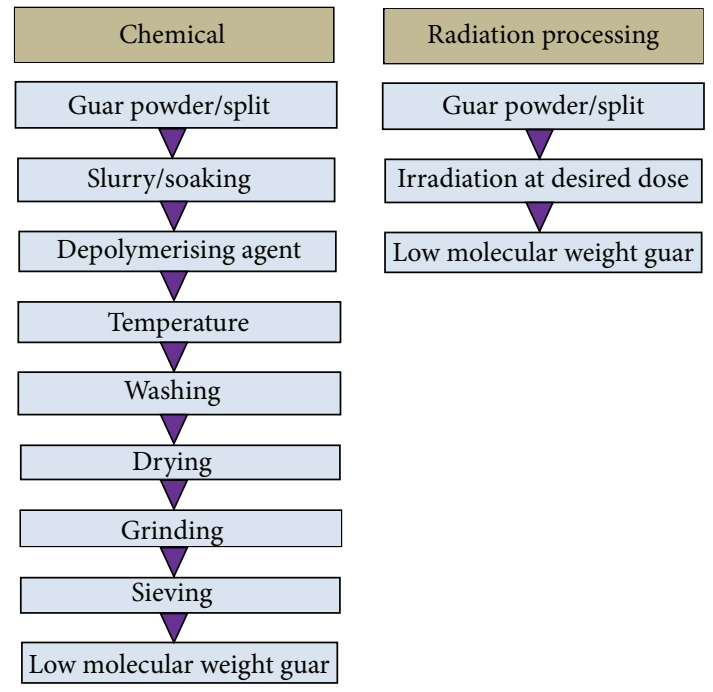

FIGURE 1: Comparison of the processing steps involved in depolymerisation of guar by Chemical Synthesis Route.

finely grounded to pass $200 \mu \mathrm{m}$ sieves before subjecting them to irradiation. The irradiation was carried out on $200 \mathrm{~g}$ batch size in case of all the specimens at each dose.

2.3. Preparation of Solutions. The moisture content of every sample was determined by heating the sample in an air circulating oven till constant weight. Aqueous solutions of $1 \%$ were prepared after applying the moisture correction factor. The desired amount of sample was weighed and dissolved in required amount of water using either an overhead motorized stirrer or a magnetic stirrer. Three hours of stirring was given to each sample before allowing it to stand overnight at ambient conditions. The following day the solution was considered ready for the rheological evaluation.

2.4. Rheological Evaluation. The rheology study of $1 \%$ aqueous solutions of guar gum and its hydroxypropyl (M.S. = 0.1 and 0.2 ), carboxymethyl (D.S. $=0.1$ and 0.2 ), and methyl derivatives (D.S. $=0.1$ and 0.2 ) was carried out on the Rheometer (MARS, Thermo Fisher) at $25^{\circ} \mathrm{C}$ temperature. The linear viscoelastic range was determined from the amplitude sweep by varying the shear stress at a constant frequency of $1 \mathrm{~Hz}$. Next, the frequency sweep was carried out at a shear stress (or amplitude value) lying in the linear viscoelastic region. The effect of shear rate on the viscosity of samples was also determined by studying the change in viscosity with varying shear rate from 1 to $30 \mathrm{rpm}$.

\section{Results and Discussion}

Guar gum and its derivatives of carboxymethyl, hydroxypropyl, and methyl derivatives with 0.1 and $0.2 \mathrm{DS} / \mathrm{MS}$ were studied by rheology before and after gamma irradiation to understand the effect of radiation on the viscosity of the sample. The effect of ionizing radiation on polysaccharides is 
TABLE 2: Crossover frequencies of guar and its various derivatives.

\begin{tabular}{lcccccc}
\hline \multirow{2}{*}{ Radiation dose (KGy) } & \multicolumn{5}{c}{ Crossover frequency (Hz) } \\
& CMG (D.S. = 0.1) & CMG (D.S. = 0.2) & HEG (M.S. =0.1) & HEG (M.S. =0.2) & MG (D.S. = 0.1) & MG (D.S. = 0.2) \\
\hline 0 & Nil & 0.299 & 0.161 & 0.134 & Nil & 0.167 \\
1 & 2.101 & 6.539 & 2.717 & 0.5298 & Nil & 0.514 \\
2.5 & 6.755 & 8.94 & 6.776 & 4.234 & 4.443 & 4.995 \\
5 & 16.91 & 22.23 & 18.40 & 9.86 & 12.24 & 10.58 \\
10 & 10.53 & 9.191 & 14.60 & 12.69 & 12.18 & 15.39 \\
20 & 3.857 & 3.275 & 2.717 & 8.335 & 6.755 & 6.959 \\
50 & 1.78 & 1.282 & 1.588 & 1.862 & Nil & 2.591 \\
\hline
\end{tabular}

known to cause degradation with a consequent loss in the viscosity. The derivatives of polysaccharides like carboxymethyl derivative of cellulose are, however, known to result in formation of gel when their aqueous solutions are subjected to an appropriate radiation dose. The competition between radiation-induced chain scission and chain crosslinking influences the resulting viscosity or formation of gel by the polysaccharide after irradiation. Thus, polysaccharides can be modified using ionizing radiation provided there is a possibility of reducing chain scission and/or favoring chain crosslinking during irradiation.

The following sections discuss the rheology studies for each sample separately.

3.1. Study on Change in Storage Modulus and Loss Modulus. The plot obtained from the frequency sweep study gives the effect of change in frequency on the storage (elastic, $G^{\prime}$ ) and the loss (viscous, $G^{\prime \prime}$ ) moduli. The effect of radiation on the storage modulus and loss modulus was studied and the change in crossover frequencies of irradiated samples has been given in Table 2. The effect of radiation on the rheological behavior of each of the derivatives has been described separately.

3.1.1. Carboxymethyl Guar. The carboxymethyl guar (CMG) samples were irradiated and their viscoelastic behavior was studied as described in the previous section. The change in storage (elastic, $G^{\prime}$ ) and the loss (viscous, $G^{\prime \prime}$ ) moduli was studied over a range of frequency 1 to $30 \mathrm{~Hz}$ and the results obtained have been shown in Figures 2 and 3. Following inferences can be drawn from the data presented in Figures 2 and 3 and Table 2.

(i) As evident from the Figures 2 and 3, in case of CMG of D.S. 0.1, there is no crossover of the $G^{\prime}$ and $G^{\prime \prime}$ whereas in case of CMG of D.S. 0.2 crossover frequency is $0.29 \mathrm{~Hz}$. This shows that the elastic nature predominates throughout in case of CMG of D.S. 0.1, whereas elasticity dominates only after frequency of $0.29 \mathrm{~Hz}$ in case of CMG of D.S. 0.2.

(ii) As shown in Table 2, the crossover frequency increases as the radiation dose increases up to $5 \mathrm{KGy}$ and the value is higher in case of CMG of D.S. 0.2 than CMG of D.S. 0.1. This shows that the elastic nature is more dominating for CMG of D.S. 0.1 than CMG of D.S. 0.2. The explanation for this can be found in the fact that initially the chains in guar gum form $\mathrm{H}$ bonding linkages in themselves leading to solid-like behavior. But as the carboxymethyl $\left(-\mathrm{CH}_{2} \mathrm{COONa}\right)$ substitution is carried out on the guar chain, the distance between the chains increases leading to opening up of the chains as the H-bonding linkages get decreased. Thus solid-like behavior or elasticity decreases on increasing the substitution.

(iii) This can also be explained by saying that during frequency sweep study, the chains get pushed towards each other and form aggregates. The carboxymethyl group being an ionic group will cause repulsion amongst the chains due to repulsion between likecharged moieties. Thus, a greater frequency will be needed to push the chains together in case of a sample having higher ionic substituents, that is, CMG of D.S. $=0.2$, to form aggregates leading to solid-like or elastic behavior.

(iv) Beyond $5 \mathrm{KGy}$ radiation dose, the crossover frequency is very close for both CMGs because the molecular chain breaks on irradiation leading to formation of small oligomeric chains of similar size in both CMGs of D.S. of 0.1 and 0.2. Thus, the effect of frequency is felt equally by both these samples.

(v) The values of $G^{\prime}$ and $G^{\prime \prime}$ are seen to decrease with the increase in radiation dose, which indicates chain scissioning.

Another aspect is the effect of radiation on the carboxymethyl guar. As seen from Table 2, the crossover frequency increases with the increase in radiation dose up to $5 \mathrm{KGy}$ and then it starts to decrease. Irradiation leads to breaking up of the chain leading to reduction in molecular weight. Up to $5 \mathrm{KGy}$ radiation dose, chain scissioning is taking place leading to decrease in molecular weight and less interaction of the smaller chains formed. As the interaction between the chains decreases, viscous behavior predominates or in other words elasticity or the solid-like behavior gets decreased. Now, beyond $5 \mathrm{KGy}$ radiation dose, it is observed that the crossover frequency gets decreased, which may signify formation of aggregates between the chains leading to more solid-like behavior at lower frequencies. 


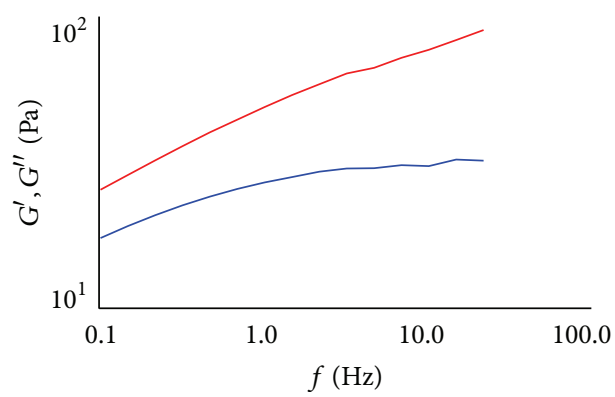

(a) CMG D.S. $=0.1 ; 0 \mathrm{KGy}$

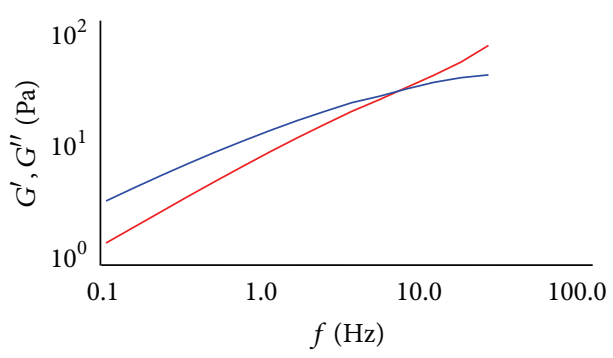

(c) CMG D.S. $=0.1 ; 2.5 \mathrm{KGy}$

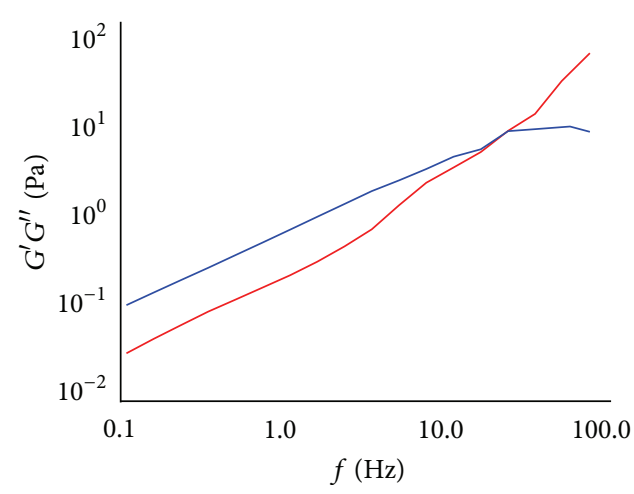

(e) CMG D.S. $=0.1 ; 10 \mathrm{KGy}$

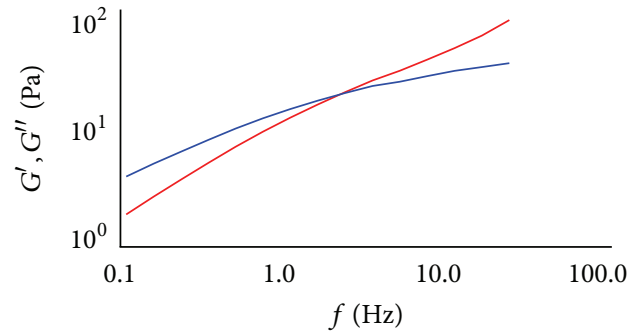

(b) CMG D.S. $=0.1 ; 1 \mathrm{KGy}$

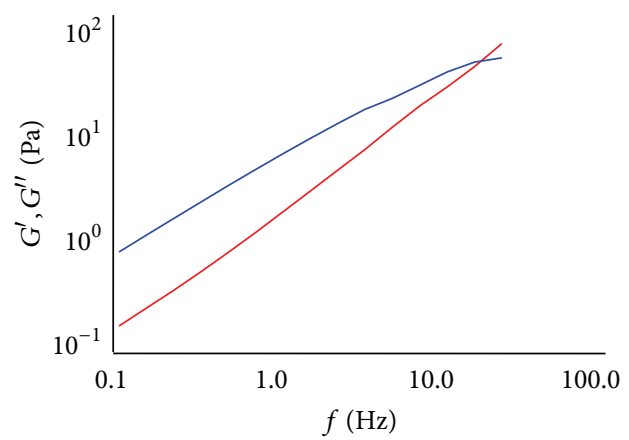

(d) CMG D.S. $=0.1 ; 5 \mathrm{KGy}$

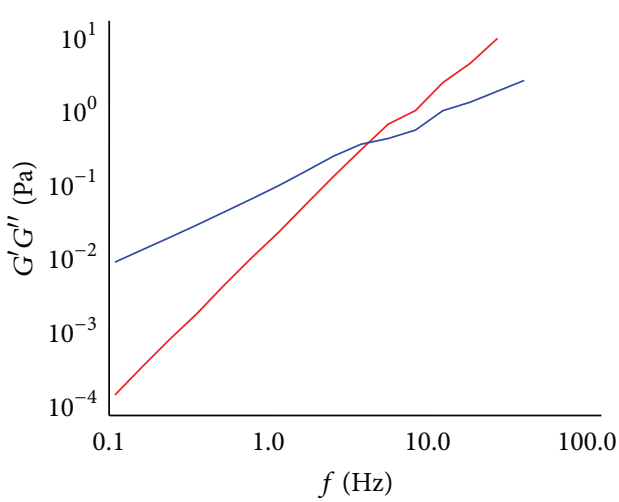

(f) $\mathrm{CMG}$ D.S. $=0.1 ; 20 \mathrm{KGy}$

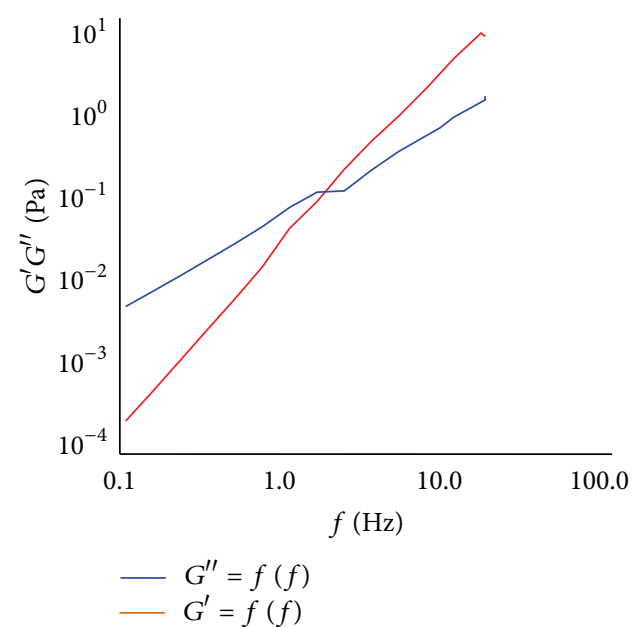

(g) CMG D.S. $=0.1 ; 50 \mathrm{KGy}$

FIGURE 2: Effect of radiation processing on the viscoelastic behavior of carboxymethylated guar (CMG) of degree of substitution (D.S.) = 0.1: (a) unirradiated; (b) irradiated at $1 \mathrm{KGy}$; (c) irradiated at $2.5 \mathrm{KGy}$; (d) irradiated at $5 \mathrm{KGy}$; (e) irradiated at $10 \mathrm{KGy}$; (f) irradiated at $20 \mathrm{KGy}$; (g) irradiated at $50 \mathrm{KGy}$. 


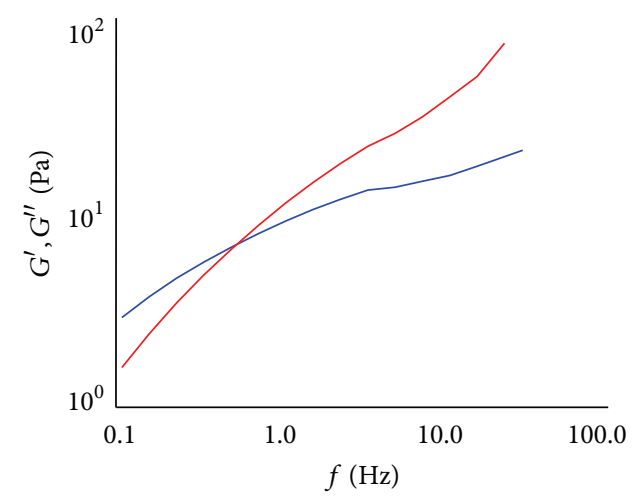

(a) CMG D.S. $=0.2 ; 0 \mathrm{KGy}$

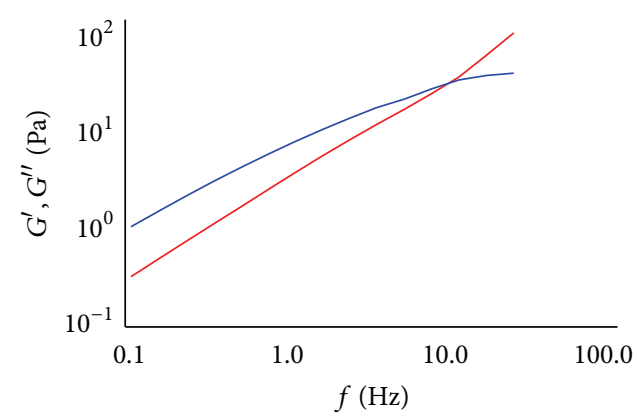

(c) CMG D.S. $=0.2 ; 2.5 \mathrm{KGy}$

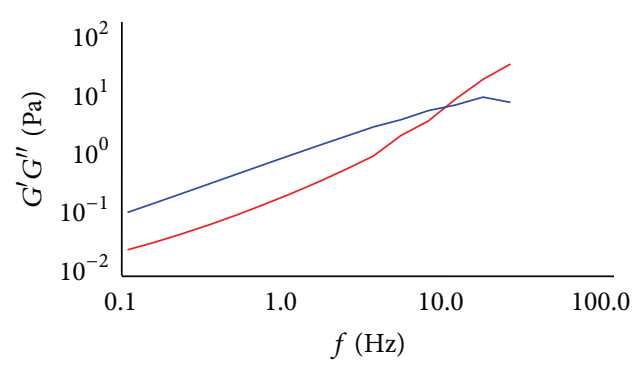

(e) CMG D.S. $=0.2 ; 10 \mathrm{KGy}$

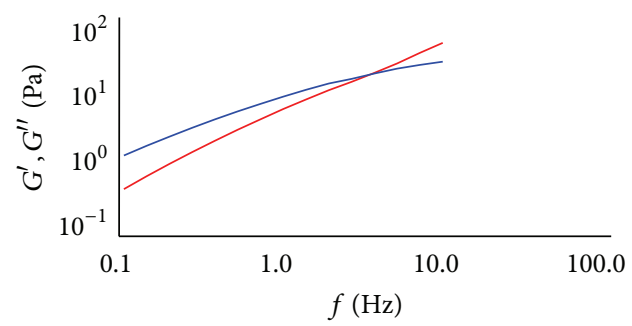

(b) CMG D.S. $=0.2 ; 1 \mathrm{KGy}$

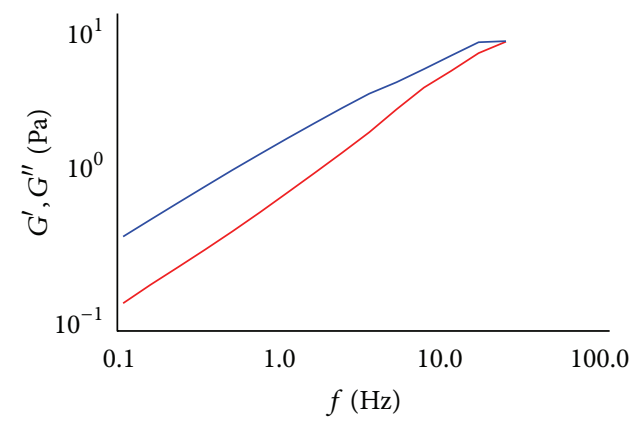

(d) CMG D.S. $=0.2 ; 5 \mathrm{KGy}$

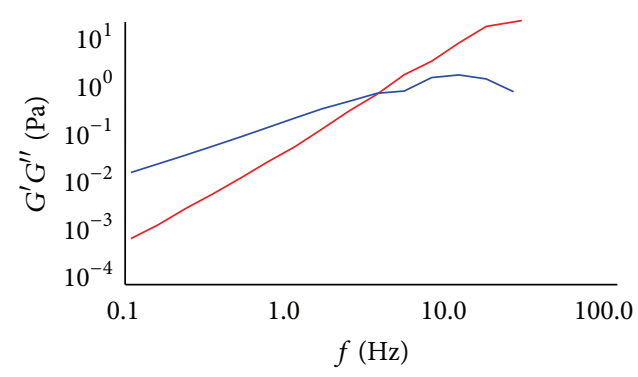

(f) CMG D.S. $=0.2 ; 20 \mathrm{KGy}$

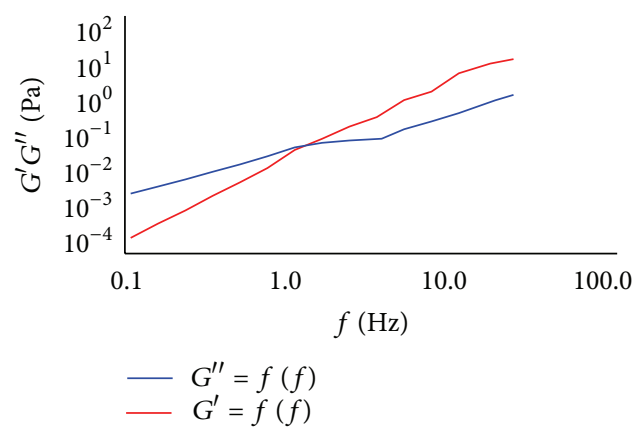

(g) CMG D.S. $=0.2 ; 50 \mathrm{KGy}$

FIGURE 3: Effect of radiation processing on the viscoelastic behavior of carboxymethylated guar (CMG) of degree of substitution (D.S.) = 0.2: (a) unirradiated; (b) irradiated at $1 \mathrm{KGy}$; (c) irradiated at $2.5 \mathrm{KGy}$; (d) irradiated at $5 \mathrm{KGy}$; (e) irradiated at $10 \mathrm{KGy}$; (f) irradiated at $20 \mathrm{KGy}$; (g) irradiated at $50 \mathrm{KGy}$.

3.1.2. Hydroxyethyl Guar. The hydroxyethyl guar (HEG) samples were irradiated and their viscoelastic behavior was studied as described in the previous section. The change in storage (elastic, $G^{\prime}$ ) and the loss (viscous, $G^{\prime \prime}$ ) moduli was studied over a range of frequency 1 to $30 \mathrm{~Hz}$ and the results obtained have been shown in Figures 4 and 5. On the basis of the results obtained, the following observations were made.

(i) As evident from Figures 4 and 5, in case of HEG of M.S. 0.2 , the crossover frequency of the $G^{\prime}$ and 


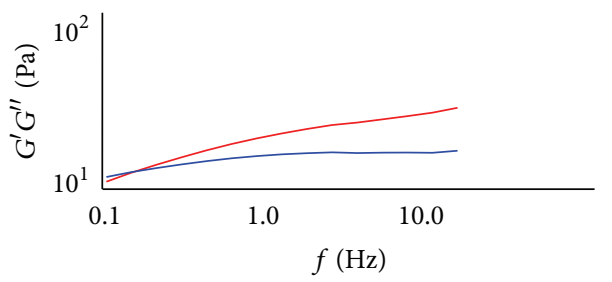

(a) HEG M.S. $=0.1 ; 0 \mathrm{KGy}$

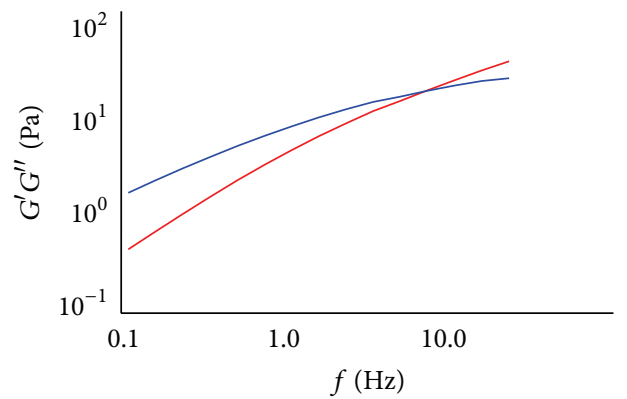

(c) HEG M.S. $=0.1 ; 2.5 \mathrm{KGy}$

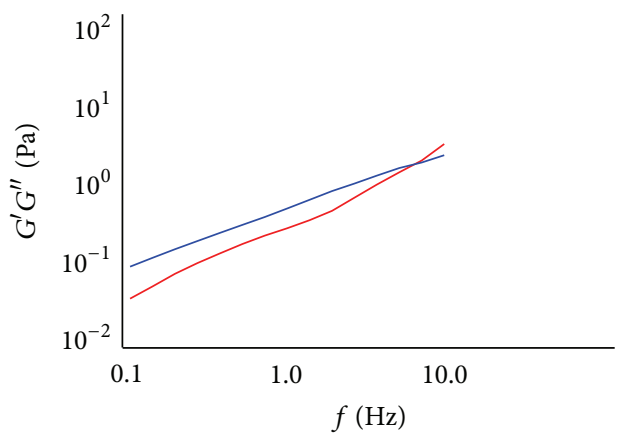

(e) HEG M.S. $=0.1 ; 10 \mathrm{KGy}$

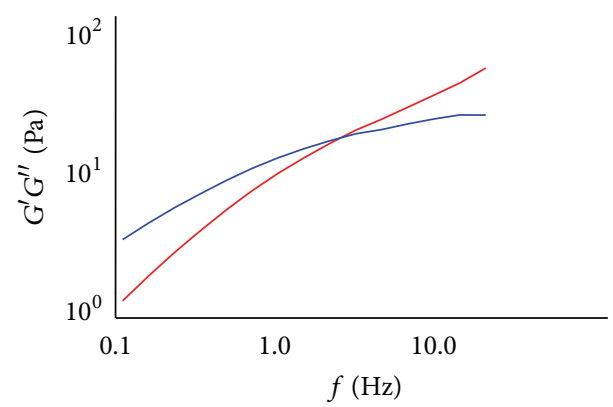

(b) HEG M.S. $=0.1 ; 1 \mathrm{KGy}$

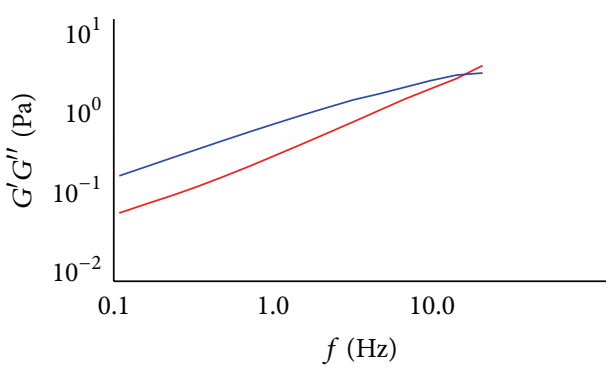

(d) HEG M.S. $=0.1 ; 5 \mathrm{KGy}$

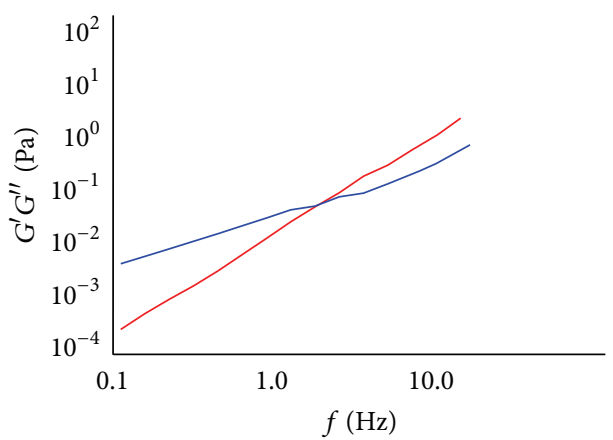

(f) HEG M.S. $=0.1 ; 20 \mathrm{KGy}$

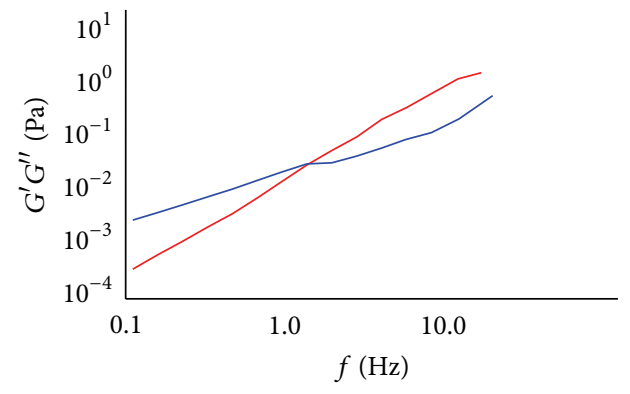

$-G^{\prime \prime}=f(f)$

— $G^{\prime}=f(f)$

(g) HEG M.S. $=0.1 ; 50 \mathrm{KGy}$

FIGURE 4: Effect of radiation processing on the viscoelastic behavior of hydroxyethylated guar (HEG) of molar substitution (M.S.) = 0.1: (a) unirradiated; (b) irradiated at $1 \mathrm{KGy}$; (c) irradiated at $2.5 \mathrm{KGy}$; (d) irradiated at $5 \mathrm{KGy}$; (e) irradiated at $10 \mathrm{KGy}$; (f) irradiated at $20 \mathrm{KGy}$; (g) irradiated at $50 \mathrm{KGy}$. 


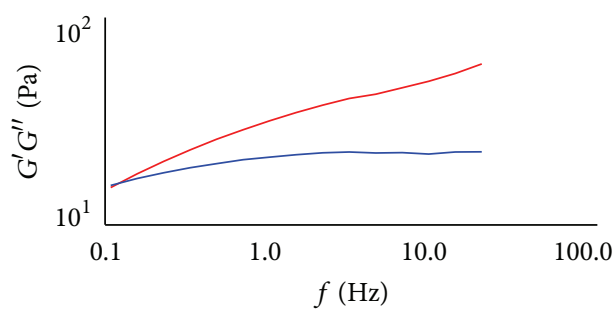

(a) HEG M.S. $=0.2 ; 0$ KGy

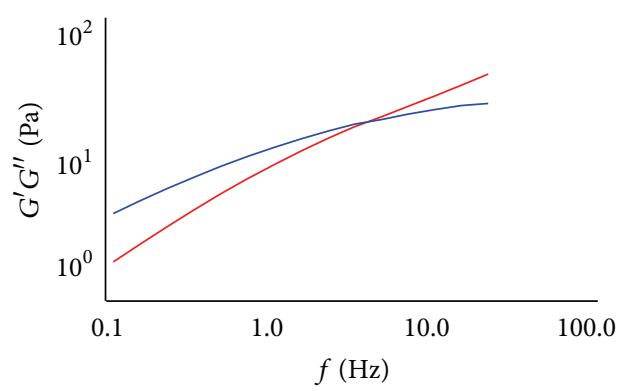

(c) HEG M.S. $=0.2 ; 2.5 \mathrm{KGy}$

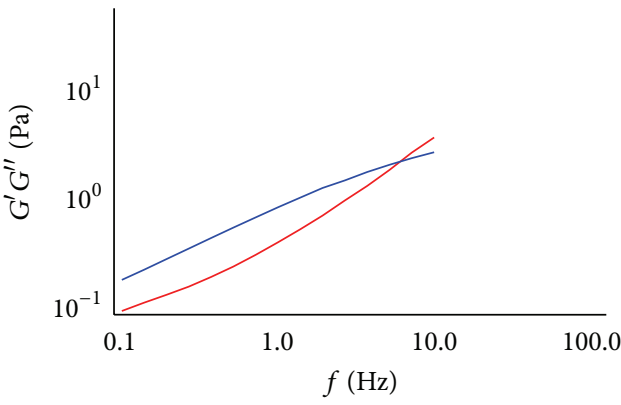

(e) HEG M.S. $=0.2 ; 10 \mathrm{KGy}$

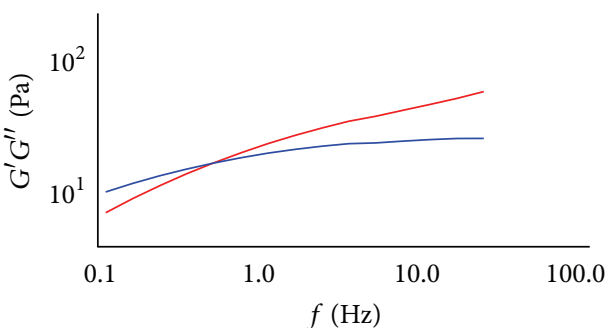

(b) HEG M.S. $=0.2 ; 1 \mathrm{KGy}$

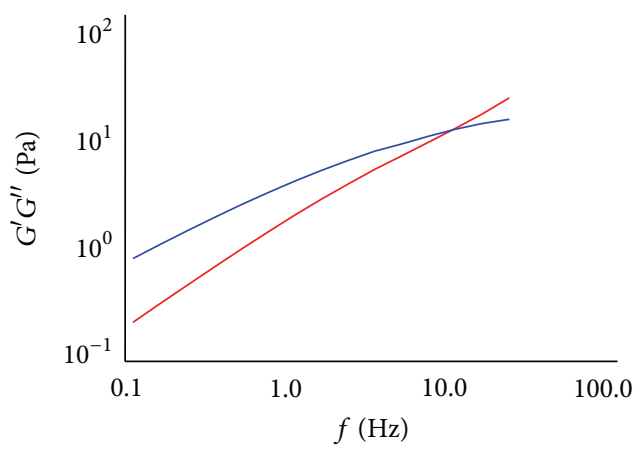

(d) HEG M.S. $=0.2 ; 5 \mathrm{KGy}$

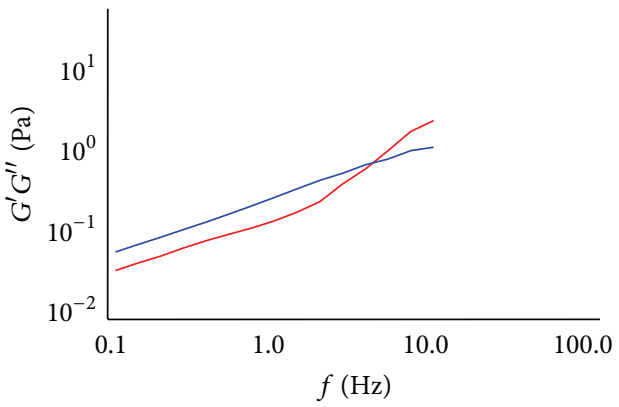

(f) HEG M.S. $=0.2 ; 20 \mathrm{KGy}$

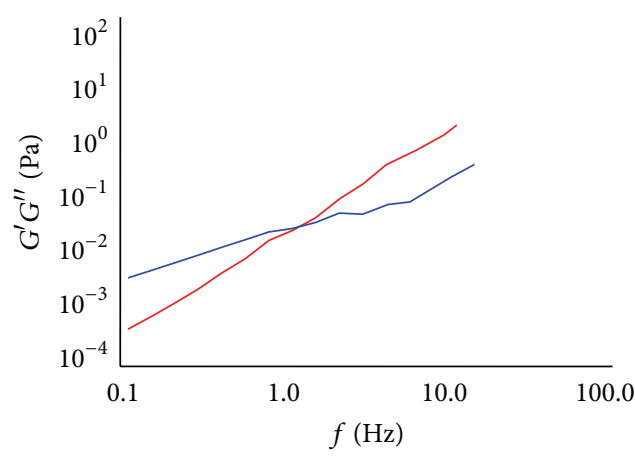

$-G^{\prime \prime}=f(f)$

- $G^{\prime}=f(f)$

(g) HEG M.S. $=0.2 ; 50 \mathrm{KGy}$

FIGURE 5: Effect of radiation processing on viscoelastic properties of hydroxyethyl guar (HEG) having molar substitution 0.2: (a) unirradiated; (b) irradiated at $1 \mathrm{KGy}$; (c) irradiated at $2.5 \mathrm{KGy}$; (d) irradiated at $5 \mathrm{KGy}$; (e) irradiated at $10 \mathrm{KGy}$; (f) irradiated at $20 \mathrm{KGy}$; (g) irradiated at $50 \mathrm{KGy}$. 
$G^{\prime \prime}$ is lesser than that of HEG of M.S. 0.1 till 20 KGy radiation dose. This means that elastic nature predominates in case of HEG of M.S. 0.2, which may be due to the presence of greater number of $-\left(\mathrm{CH}_{2}-\mathrm{O}\right)_{n}{ }^{-}$ $\mathrm{H}$ groups leading to increase in $\mathrm{H}$-bonding and thus more solid-like behavior.

(ii) On comparing the crossover frequencies of HEG of M.S. 0.1 after irradiation, it can be seen from the data that crossover frequency increases till $5 \mathrm{KGy}$ dose and then it decreases, whereas in case of HEG of M.S. 0.2, the crossover frequency increases till $10 \mathrm{KGy}$ dose and then it decreases. This can be explained on the basis of interactions taking place between the macromolecular chains in these two HEGs. In case of HEG of M.S. 0.1, intermolecular interactions are less as compared to HEG of M.S. 0.2 and thus less elastic nature.

(iii) Also, in case of HEG of M.S. 0.2, as the substitution increases, the coiling of macromolecular chain decreases due to steric hindrance, thereby causing more intramolecular interactions than intermolecular interactions. Less coiling of the chain causes more exposure to irradiation and thus greater chain scissioning and more viscous response of the macromolecule.

(iv) As the radiation dose increases, there is more chain scissioning leading to formation of oligomeric chains. These chains form intermolecular hydrogen bonding linkages leading to elastic behavior at lower frequencies.

(v) The $G^{\prime}$ and $G^{\prime \prime}$ values decrease on increasing the radiation dose, which signifies chain scissioning.

3.1.3. Methyl Guar. The methyl guar (MG) samples were irradiated and their viscoelastic behavior was studied as described in the previous section. The change in storage (elastic, $G^{\prime}$ ) and the loss (viscous, $G^{\prime \prime}$ ) moduli was studied over a range of frequency 1 to $30 \mathrm{~Hz}$ and the results obtained have been shown in Figures 6 and 7.

The following observations were made from the results.

In case of MG of D.S. 0.1, no crossover of $G^{\prime}$ and $G^{\prime \prime}$ curves is seen in unirradiated and irradiated sample at $1 \mathrm{KGy}$ dose. This shows that the elasticity predominates. Methyl group is hydrophobic in nature and its substitution reduces the number of hydroxyl groups on guar molecule and opens up the guar chains. This leads to more number of intermolecular interactions than intramolecular interactions and thus increases elasticity.

(i) On increasing the radiation dose up to $10 \mathrm{KGy}$, the elastic component decreases. This can be attributed to the fact that chain scissioning takes place and now the $\mathrm{H}$-bonding interactions take place between smaller chains, which reduces the elasticity and viscous behavior predominates. Due to this, the crossover frequency increases till $10 \mathrm{KGy}$ dose.

(ii) Beyond $10 \mathrm{KGy}$ dose, there is increase in the elastic component, which may be because of interactions in the smaller chains because of hydrophobic methyl group.

3.2. Study on Effect of Irradiation on Shear Rate. The effect of radiation on the change in viscosity with increase in shear rate (1 to 30/s) was studied and has been shown in Figures 8 to 13 . To analyze this data, the minimum viscosity (viscosity obtained at shear rate value of 30/s) obtained for each of the samples was plotted against the radiation dose (Figure 14) and the shear rate at which shear rate versus viscosity curve reaches a plateau was plotted with respect to the increase in radiation dose (Figure 15) for all the samples (CMG, HEG and MG).

3.3. Radiation Dose versus Viscosity. As evident from Figure 14, the minimum viscosity attained by the $1 \%$ solution of various derivatives both before and after irradiation shows a decreasing trend with respect to increase in the radiation dose. The decrease is less pronounced in the case of samples having higher substitution, which shows that samples with greater substitution level exhibit higher resistance to depolymerisation.

3.4. Radiation Dose versus Shear Rate. Figure 15 shows the effect of increasing the radiation dose on shear rate needed to achieve nearly constant viscosity with respect to change in shear rate. As the radiation dose is increased, the shear rate value, at which nearly constant viscosity is achieved, decreases and at the same time the behavior of the three types of derivatives is quite different for each type.

In case of CMG, the shear rate required to achieve nearly constant viscosity decreases with the increase in radiation dose. This means that as the radiation dose is increasing, the shear stability of carboxymethyl guar is increasing. In other words, the oligomeric chains of carboxymethyl guar formed on its irradiation exhibit better shear stability. When we look at the results obtained in case of hydroxyethyl guar, then it becomes evident that nearly constant viscosity in this case is achieved at higher shear rate values, although a decreasing trend in shear rate values is observed in this case also. In case of methyl guar also, on increasing the radiation dose, the shear rate required to achieve nearly constant viscosity decreases. In case of methyl guar of D.S. 0.1, the shear rate value was found to be nearly constant from 2.5 to $50 \mathrm{KGy}$ radiation dose.

\section{Conclusion}

The depolymerisation of polymers and polymeric materials by radiation processing is a dry technique. Further, for achieving the desired results, one does not have to use any of the additives. In other words, by radiation processing one can depolymerize guar powder as such without making its solution in water and without incorporation of additives.

Radiation processing of materials such as polymers, food products, precious stones, medical goods, has been widely adopted industrially since it is a continuous operation, which is highly precise, energy saving, and reproducible. 


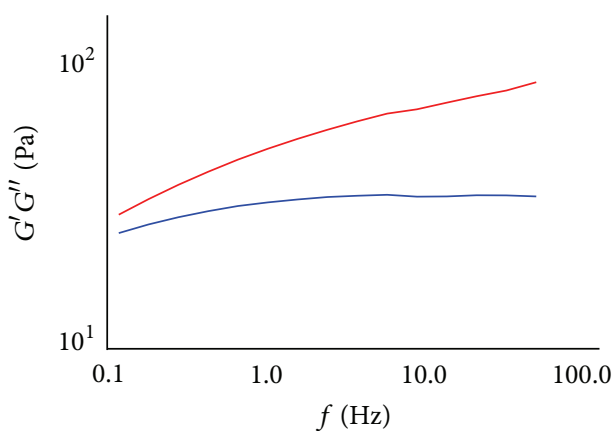

(a) MG D.S. $=0.1 ; 0 \mathrm{KGy}$

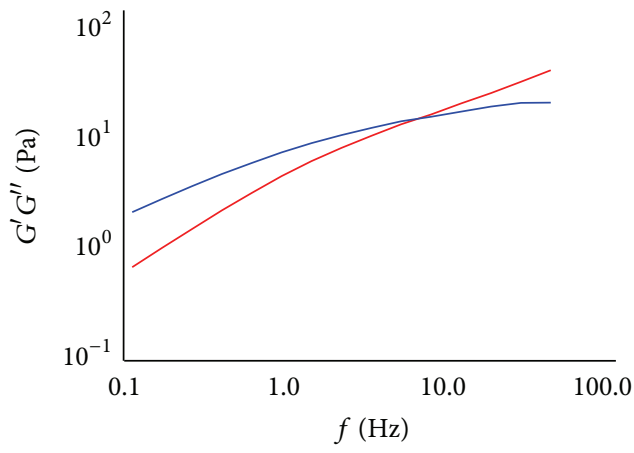

(c) MG D.S. $=0.1 ; 2.5 \mathrm{KGy}$

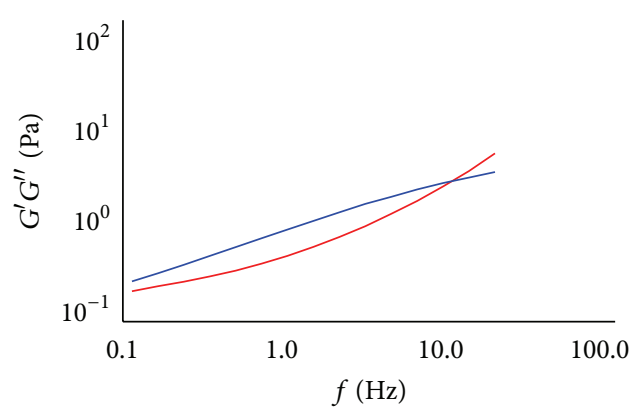

(e) MG D.S. $=0.1 ; 10 \mathrm{KGy}$

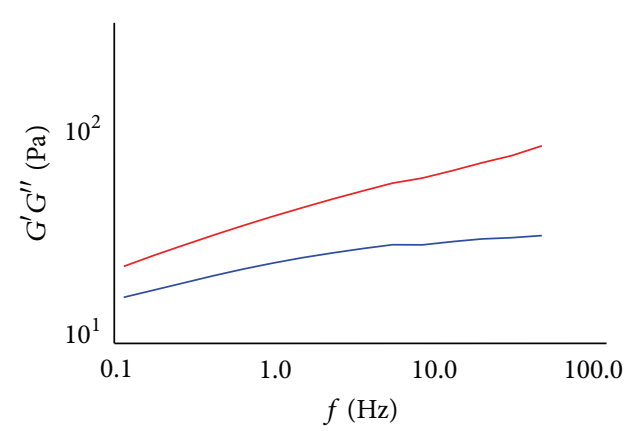

(b) MG D.S. $=0.1 ; 1 \mathrm{KGy}$

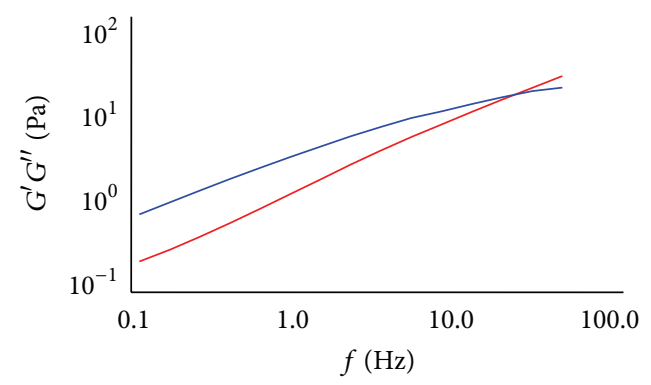

(d) $\mathrm{MG}$ D.S. $=0.1 ; 5 \mathrm{KGy}$

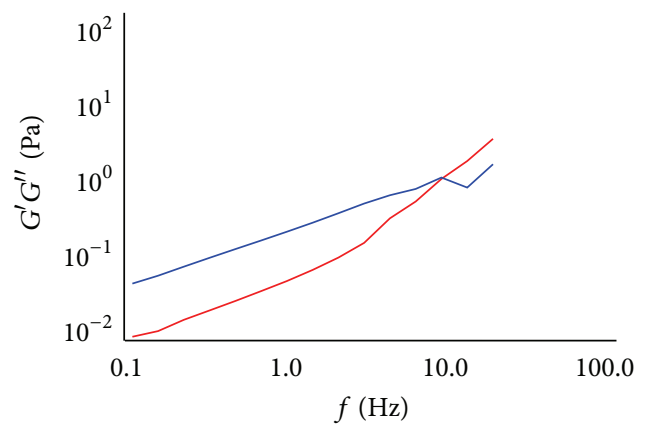

(f) MG D.S. $=0.1 ; 20 \mathrm{KGy}$

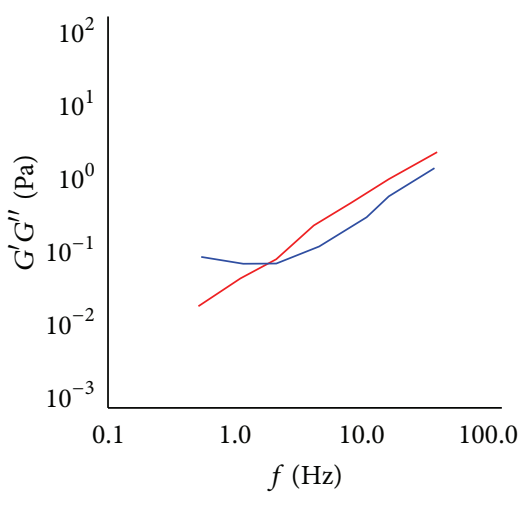

$$
\begin{aligned}
G^{\prime \prime} & =f(\mathrm{f}) \\
-G^{\prime} & =f(\mathrm{f})
\end{aligned}
$$

(g) MG D.S. $=0.1 ; 50 \mathrm{KGy}$

FIGURE 6: Effect of radiation processing on the viscoelastic behavior of methylated guar (MG) of degree of substitution (D.S.) = 0.1: (a) unirradiated; (b) irradiated at $1 \mathrm{KGy}$; (c) irradiated at $2.5 \mathrm{KGy}$; (d) irradiated at $5 \mathrm{KGy}$; (e) irradiated at $10 \mathrm{KGy}$; (f) irradiated at $20 \mathrm{KGy}$; (g) irradiated at $50 \mathrm{KGy}$. 


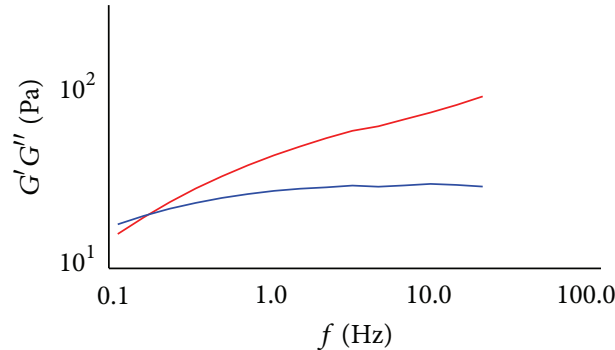

(a) MG D.S. $=0.2 ; 0 \mathrm{KGy}$

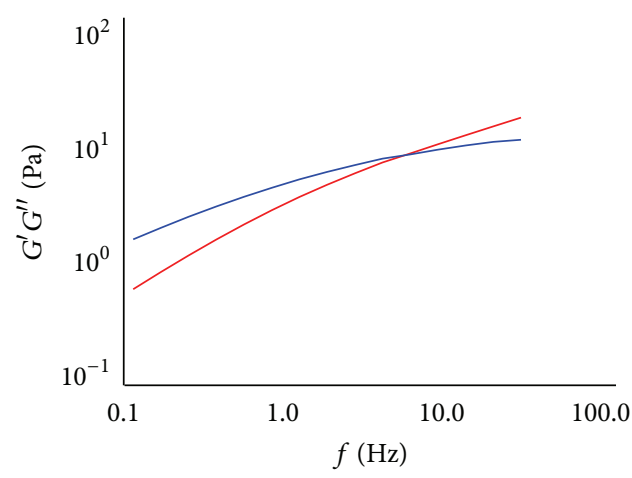

(c) MG D.S. $=0.2 ; 2.5 \mathrm{KGy}$

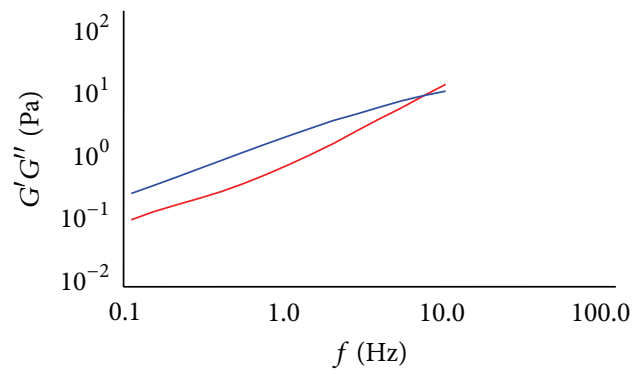

(e) MG D.S. $=0.2 ; 10 \mathrm{KGy}$

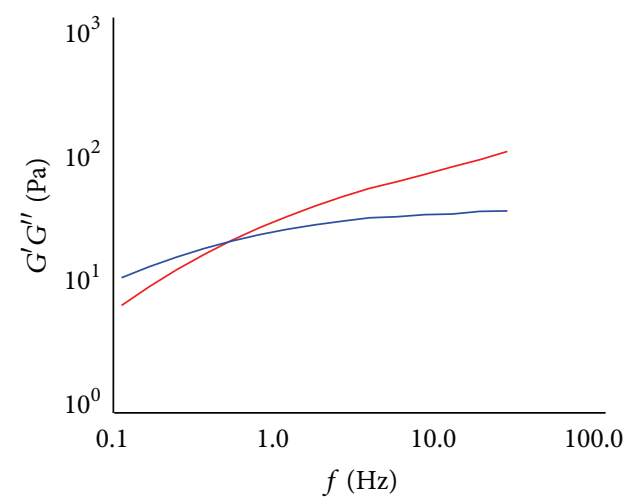

(b) $\mathrm{MG}$ D.S. $=0.2 ; 1 \mathrm{KGy}$

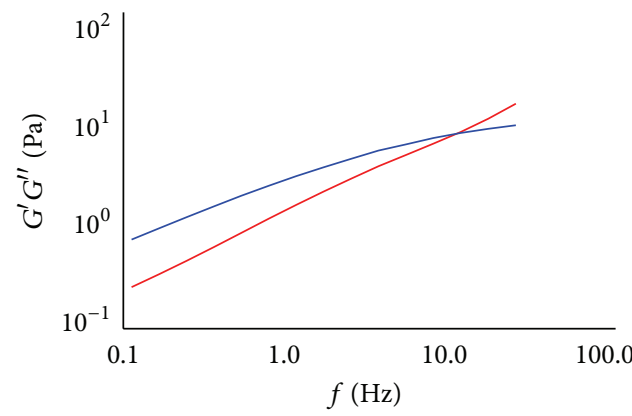

(d) MG D.S. $=0.2 ; 5 \mathrm{KGy}$

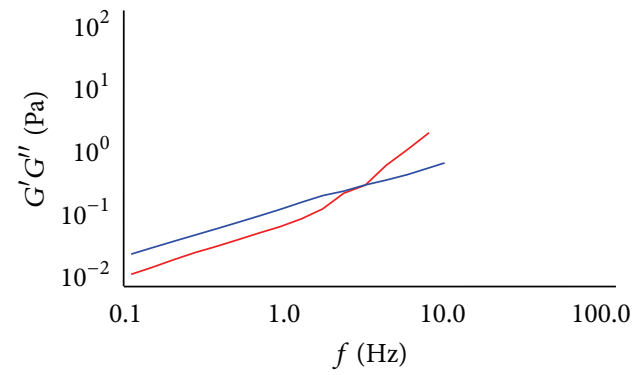

(f) MG D.S. $=0.2 ; 20 \mathrm{KGy}$

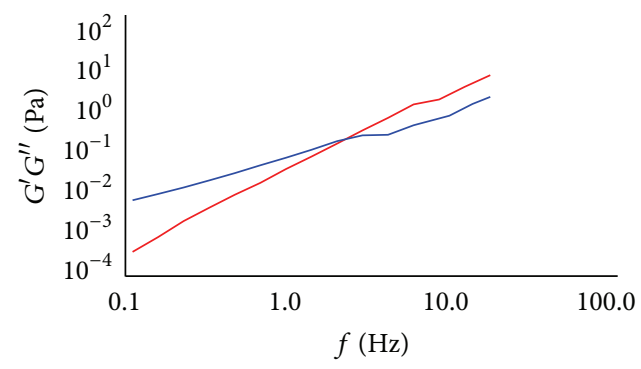

$$
\begin{aligned}
G^{\prime \prime} & =f(\mathrm{f}) \\
-G^{\prime} & =f(\mathrm{f})
\end{aligned}
$$

(g) MG D.S. $=0.2 ; 50 \mathrm{KGy}$

FIGURE 7: Effect of radiation processing on the viscoelastic behavior of methylated guar (MG) of degree of substitution (D.S.) = 0.2: (a) unirradiated; (b) irradiated at $1 \mathrm{KGy}$; (c) irradiated at $2.5 \mathrm{KGy}$; (d) irradiated at $5 \mathrm{KGy}$; (e) irradiated at $10 \mathrm{KGy}$; (f) irradiated at $20 \mathrm{KGy}$; (g) irradiated at $50 \mathrm{KGy}$. 


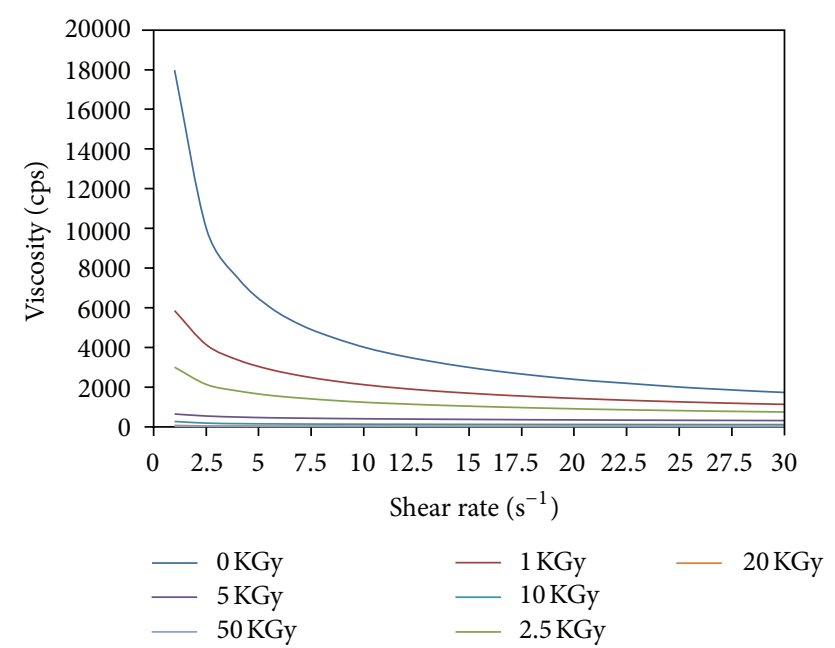

FIGURE 8: Effect of radiation processing on the shear stability of carboxymethylated guar (CMG) of degree of substitution (D.S.) = 0.1 ; unirradiated and irradiated.

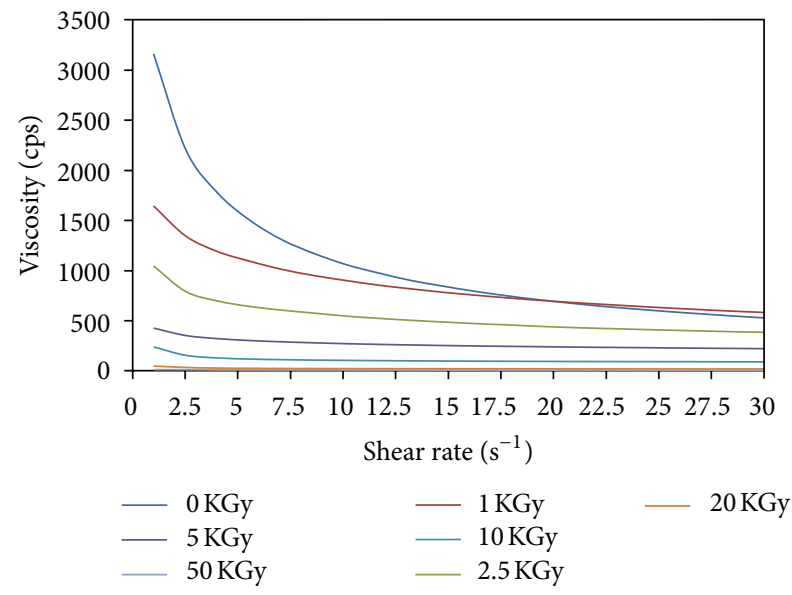

FIGURE 9: Effect of radiation processing on the shear stability of carboxymethylated guar (CMG) of degree of substitution (D.S.) = 0.2 ; unirradiated and irradiated.

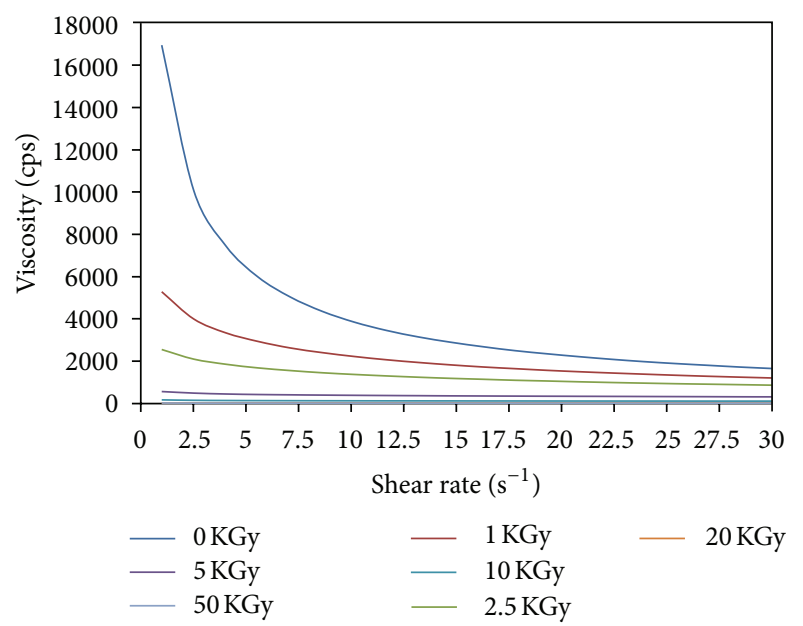

FIGURE 10: Effect of radiation processing on the shear stability of hydroxyethylated guar (HEG) of molar substitution (M.S.) = 0.1; unirradiated and irradiated.

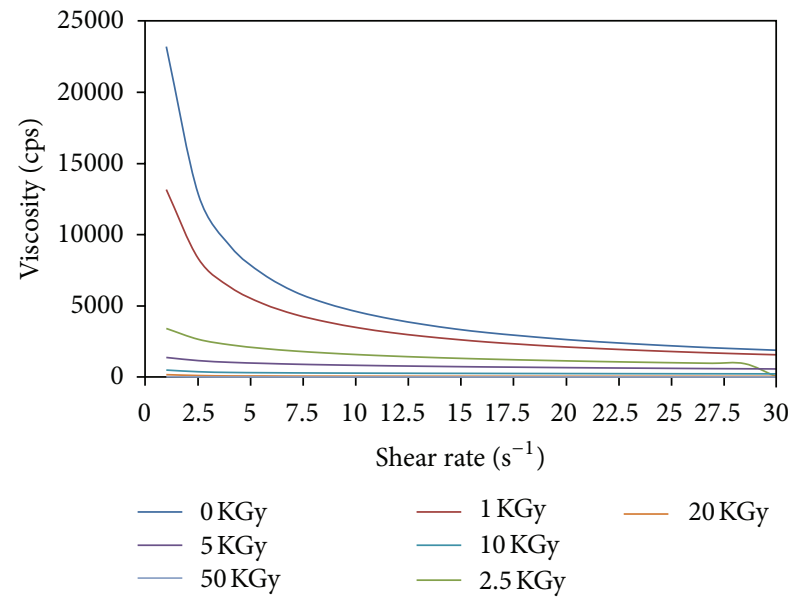

FIGURE 11: Effect of radiation processing on the shear stability of hydroxyethylated guar (HEG) of molar substitution (M.S.) $=0.2$; unirradiated and irradiated.

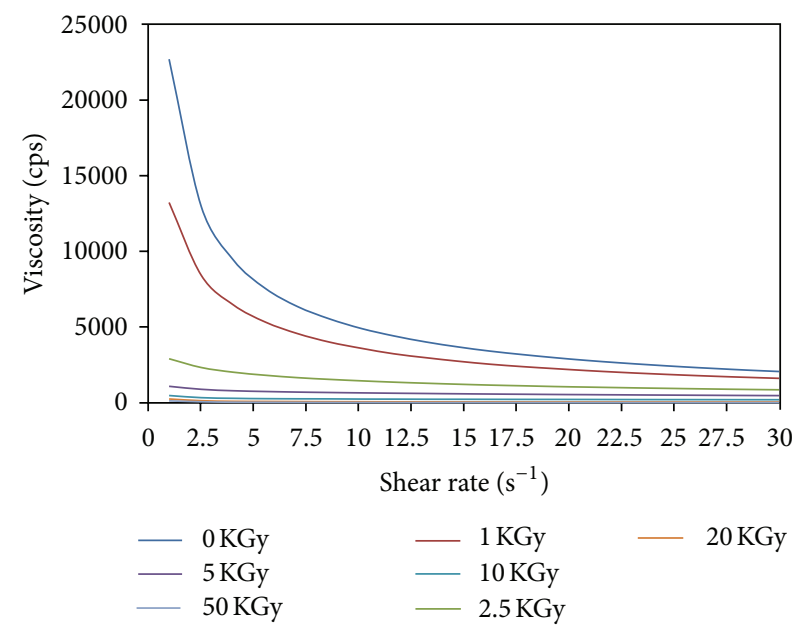

FIGURE 12: Effect of radiation processing on the shear stability of methylated guar (MG) of degree of substitution (D.S.) =0.1; unirradiated and irradiated.

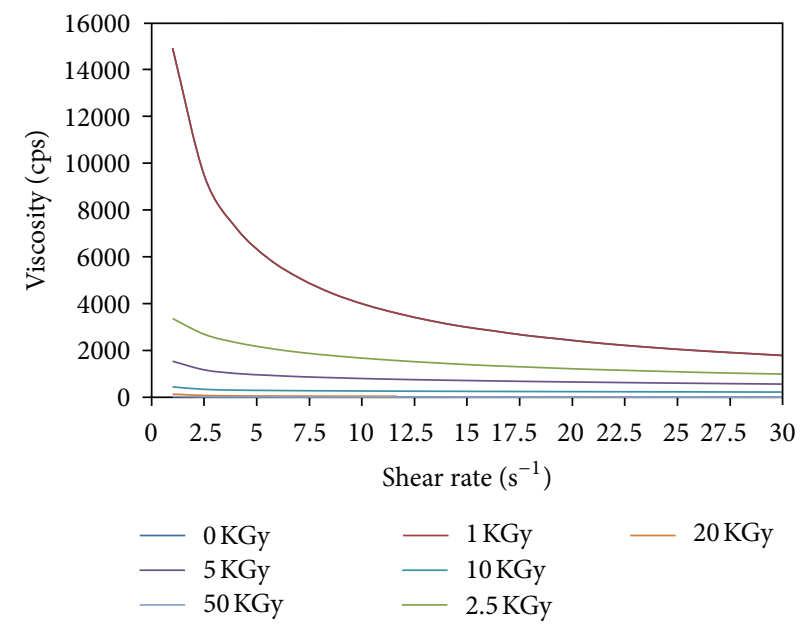

FIGURE 13: Effect of radiation processing on the shear stability of methylated guar (MG) of degree of substitution (D.S.) $=0.2$; unirradiated and irradiated. 


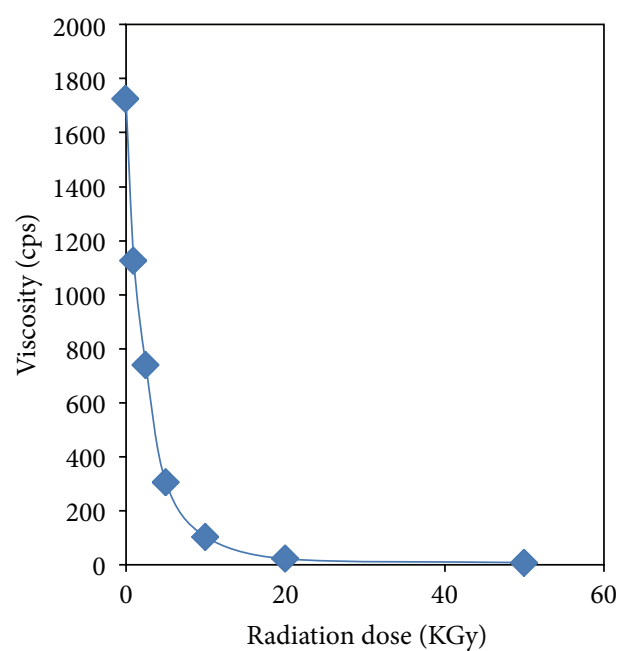

(a) $\mathrm{CMG}, \mathrm{D} . \mathrm{S} .=0.1$

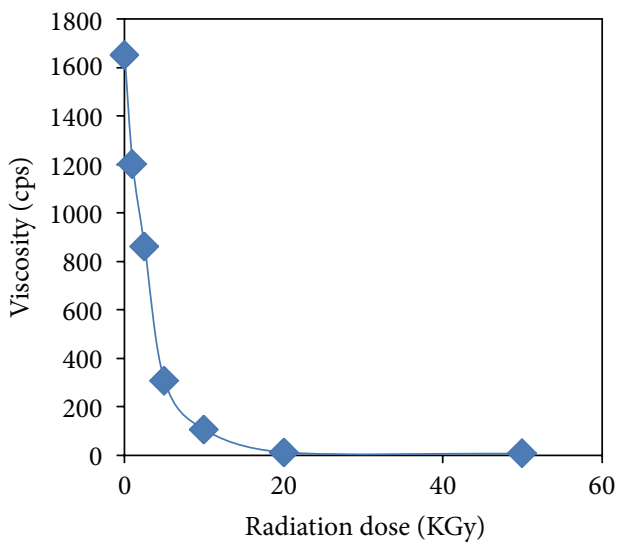

(c) HEG, M.S. $=0.1$

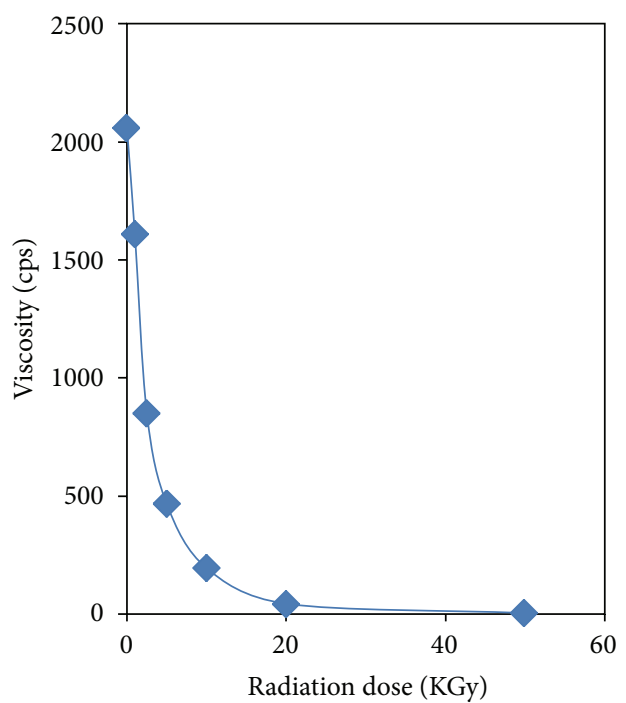

(e) MG, D.S. $=0.1$

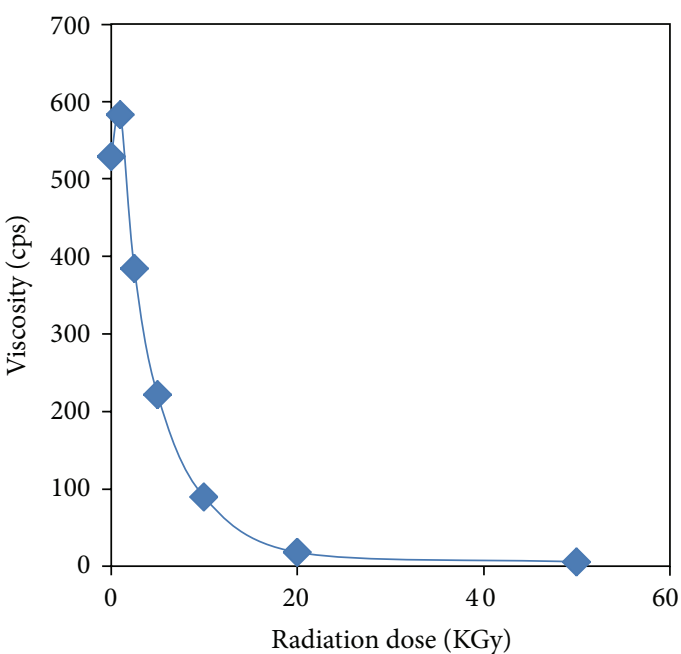

(b) CMG, D.S. $=0.2$

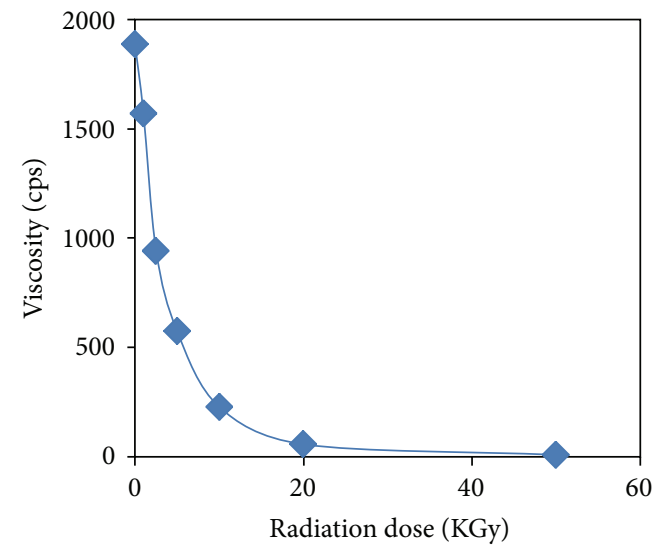

(d) HEG, M.S. $=0.2$

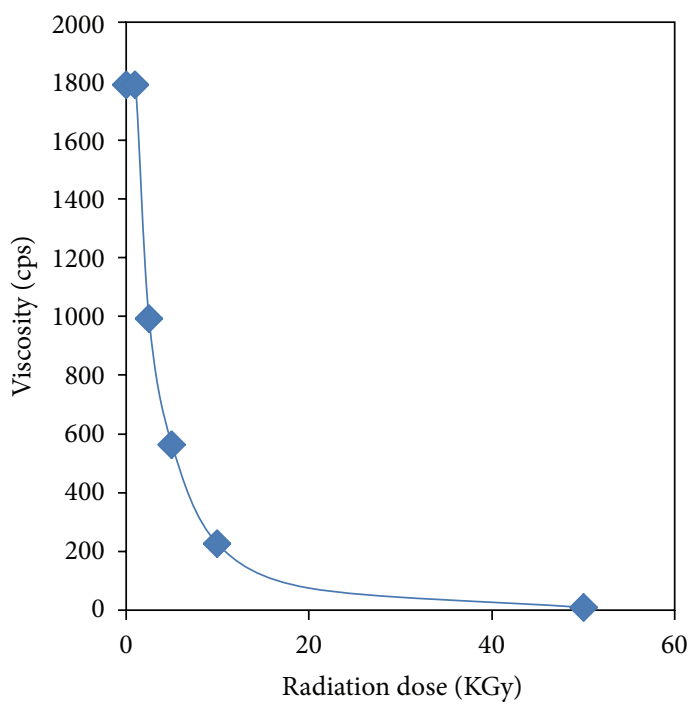

(f) $M G$, D.S. $=0.2$

FIgURE 14: The plot of minimum viscosity (at shear rate 30/s) attained by the sample while subjecting it to shear from 1 to $30 / \mathrm{s}$ for (a) CMG D.S. $=0.1$ and (b) 0.2 , (c) HEG M.S. $=0.1$ and (d) 0.2 , and (e) MG D.S. $=0.1$ and (f) 0.2 with respect to radiation dose. 


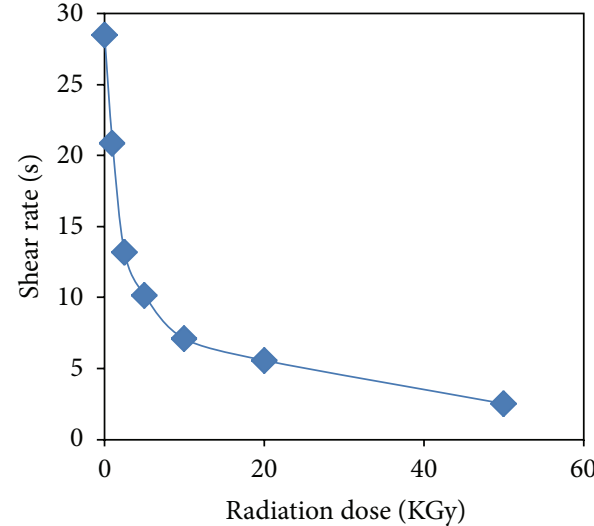

(a) CMG, D.S. $=0.1$

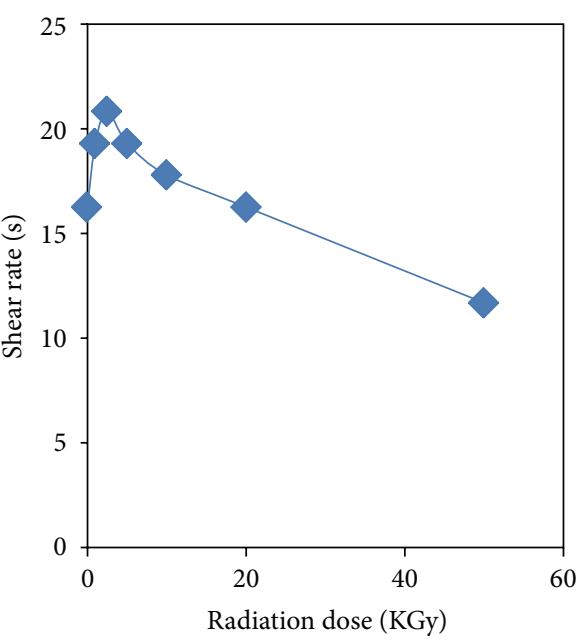

(c) HEG, M.S. $=0.1$

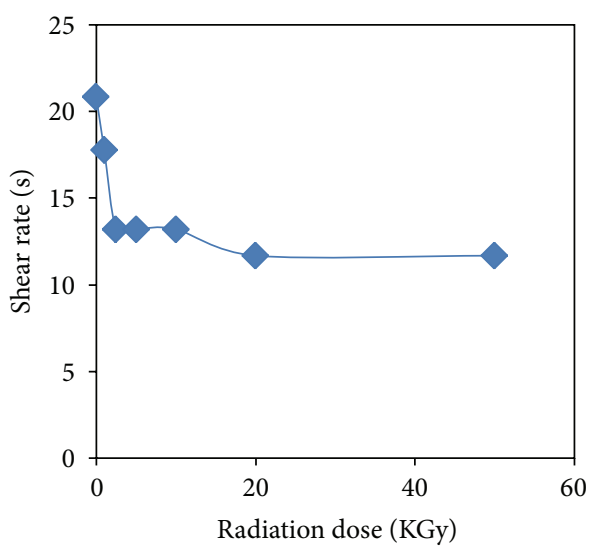

(e) MG, D.S. $=0.1$

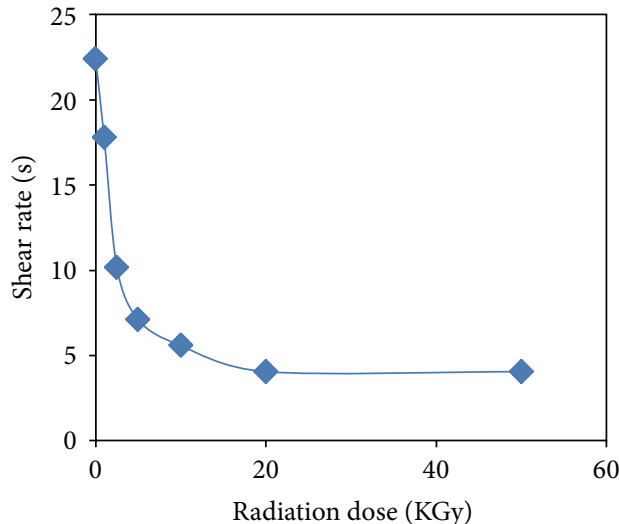

(b) CMG, D.S. $=0.2$

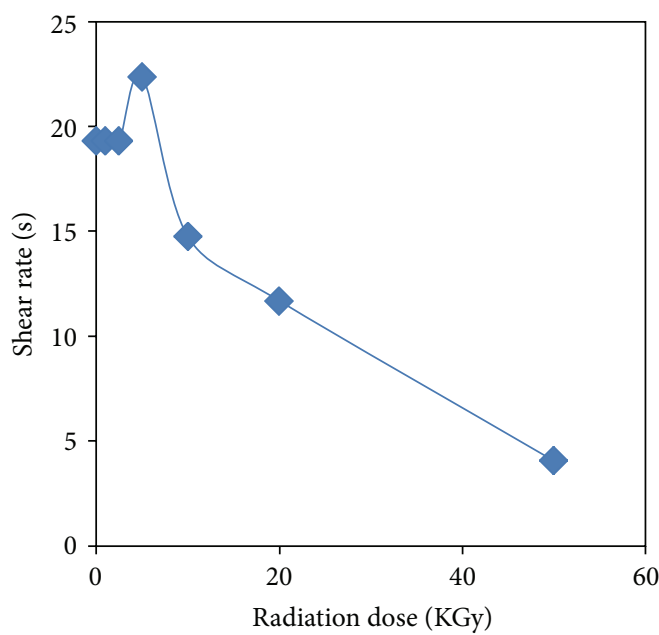

(d) HEG, M.S. $=0.2$

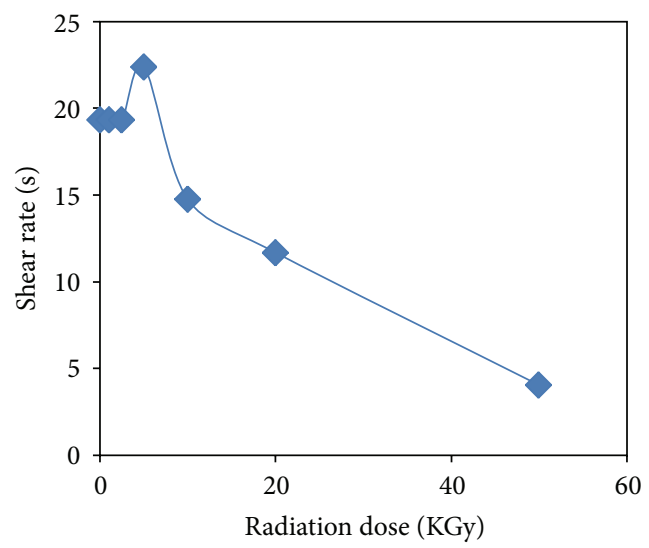

(f) $\mathrm{MG}$, D.S. $=0.2$

FIGURE 15: The plot of shear rate value versus radiation dose. The shear rate value was taken from the study carried out by increasing the shear rate and monitoring change in viscosity. The point at which the curve between shear rate and viscosity reaches plateau was taken for plotting radiation dose versus shear rate for samples (a) CMG D.S. $=0.1$ and (b) 0.2 , (c) HEG M.S. = 0.1 and (d) 0.2, and (e) MG D.S. = 0.1 and (f) 0.2 with respect to radiation dose.

The depolymerisation of synthetic polymers by radiation processing for recycling of monomers has been known for quite some time. The present paper is an attempt to initiate the use of this technology for radiation processing of modified natural polymers. The gamma irradiation facility used for the current studies is an industrial plant and it has been in operation for about 20 years now where large volumes of industrial products are irradiated every day.

From the results presented here, it is evident that the depolymerisation of guar is achieved with the radiation dose 
of $1 \mathrm{KGy}$ and above, as seen from the observation of viscosity of $1 \%$ of guar derivatives getting reduced from as high a level as $10,000 \mathrm{cps}$ (for unirradiated guar derivative) to as low a level as $1 \mathrm{cps}$ at $25^{\circ} \mathrm{C}$ (for guar derivatives irradiated at 20 50 KGy).

Inspite of this knowledge, which can be easily used for scaling up of the process to commercial level, doubts are raised about the scalability of the process. Whether the process can be used for bulk material is the common apprehension in the minds of the processors of guar. While the present study would help clear many of the doubts regarding the suitability of radiation processing technology, but the data about the scalability of the process would actually eliminate all sorts of doubts.

Eventhough, the results presented in this paper pertain to the batch size of $200 \mathrm{~g}$ for each guar derivative at each dose, the same was found valid even for the bigger batch size (in tons). The results of large batches were the same as obtained for the small batches. Here, it must be mentioned that the dose optimization for the purpose would be necessary for the purpose of studying the scalability.

From the present study the following can be concluded.

(i) Radiation processing of guar derivatives leads to their chain scissioning.

(ii) Radiation processing leads to reduction in viscosity of aqueous solutions of guar derivatives.

(iii) Irradiation technique can be a good tool for tailor making the guar derivatives of desired rheological properties.

(iv) The minimum viscosity attained by the $1 \%$ solution of various derivatives shows a decreasing trend with respect to increase in the radiation dose.

(v) In case of carboxymethyl guar, the crossover frequency increases as the radiation dose increases up to $5 \mathrm{KGy}$ and the value is higher in case of CMG of D.S. 0.2 than in that of CMG of D.S. 0.1. This shows that the elastic nature is more dominating for CMG of D.S. 0.1 than for CMG of D.S. 0.2.

(vi) In case of hydroxyethyl guar of M.S. 0.2, the crossover frequency of the $G^{\prime}$ and $G^{\prime \prime}$ is lesser than that of HEG of M.S. 0.1 till $20 \mathrm{KGy}$ radiation dose. This means that elastic nature predominates in case of HEG of M.S. 0.2, which may be due to the presence of greater number of $-\left(\mathrm{CH}_{2}-\mathrm{O}\right)_{n}-\mathrm{H}$ groups leading to increase in $\mathrm{H}$-bonding and thus more solid-like behavior.

(vii) In case of methyl guar, on increasing the radiation dose up to $10 \mathrm{KGy}$, the elastic component decreases. This can be attributed to the fact that chain scissioning takes place and now the $\mathrm{H}$-bonding interactions take place between smaller chains, which reduces the elasticity and viscous behavior predominates. Due to this, the crossover frequency increases till $10 \mathrm{KGy}$ dose.

(viii) As the radiation dose is increased, the shear rate value at which nearly constant viscosity is achieved decreases.

\section{Acknowledgment}

The authors express sincere gratitude to the management of Shriram Institute for Industrial Research, Delhi, India, for the kind support.

\section{References}

[1] L. Wang and L. M. Zhang, "Viscoelastic characterization of a new guar gum derivative containing anionic carboxymethyl and cationic 2-hydroxy-3-(trimethylammonio)propyl substituents," Industrial Crops and Products, vol. 29, no. 2-3, pp. 524529, 2009.

[2] C. Sandolo, P. Matricardi, F. Alhaique, and T. Coviello, "Effect of temperature and cross-linking density on rheology of chemical cross-linked guar gum at the gel point," Food Hydrocolloids, vol. 23, no. 1, pp. 210-220, 2009.

[3] H. N. Englyst, V. Anderson, and J. H. Cummings, "Starch and non-starch polysaccharides in some cereal foods," Journal of the Science of Food and Agriculture, vol. 34, no. 12, pp. 1434-1440, 1983.

[4] R. L. Feddersen and S. N. Thorp, Industrial Gums, Acaedemic Press, San Diego, Calif, USA, 1993.

[5] D. D. Roberts, J. S. Elmore, K. R. Langley, and J. Bakker, "Effects of sucrose, guar gum, and carboxymethylcellulose on the release of volatile flavor compounds under dynamic conditions," Journal of Agricultural and Food Chemistry, vol. 44, no. 5, pp. 1321-1326, 1996.

[6] D. R. Picout, S. B. Ross-Murphy, K. Jumel, and S. E. Harding, "Pressure cell assisted solution characterization of polysaccharides. 2. Locust bean gum and tara gum," Biomacromolecules, vol. 3, no. 4, pp. 761-767, 2002.

[7] R. S. Blackburn, "Natural polysaccharides and their interactions with dye molecules: applications in effluent treatment," Environmental Science and Technology, vol. 38, no. 18, pp. 4905-4909, 2004.

[8] M. Urdiaín, A. Doménech-Sánchez, S. Albertí, V. J. Benedí, and J. A. Rosselló, "New method of DNA isolation from two food additives suitable for authentication in polymerase chain reaction assays," Journal of Agricultural and Food Chemistry, vol. 53, no. 9, pp. 3345-3347, 2005.

[9] R. P. Singh, S. Pal, and D. Mal, "A high performance flocculating agent and viscosifiers based on cationic guar gum," Macromolecular Symposia, vol. 242, pp. 227-234, 2006.

[10] S. P. Zhao, D. Ma, and L. M. Zhang, "New semi-interpenetrating network hydrogels: synthesis, characterization and properties," Macromolecular Bioscience, vol. 6, no. 6, pp. 445-451, 2006.

[11] J. Z. Yi and L. M. Zhang, "Biodegradable blend films based on two polysaccharide derivatives and their use as Ibuprofenreleasing matrices," Journal of Applied Polymer Science, vol. 103, no. 6, pp. 3553-3559, 2007.

[12] S. Venkataiah and E. G. Mahadevan, "Rheological properties of hydroxypropyl and sodium carboxymethyl substituted guar gums in aqueous solution," Journal of Applied Polymer Science, vol. 27, no. 5, pp. 1533-1548, 1982.

[13] R. H. W. Wientjes, M. H. G. Duits, R. J. J. Jongschaap, and J. Mellema, "Linear rheology of guar gum solutions," Macromolecules, vol. 33, no. 26, pp. 9594-9605, 2000.

[14] T. Aubry and M. Moan, "Rheological behavior of a hydrophobically associating water soluble polymer," Journal of Rheology, vol. 38, no. 6, pp. 1681-1692, 1994. 
[15] L. M. Zhang, T. Kong, and P. S. Hui, "Semi-dilute solutions of hydroxypropyl guar gum: viscosity behaviour and thixotropic properties," Journal of the Science of Food and Agriculture, vol. 87, no. 4, pp. 684-688, 2007.

[16] N. N. G. Swamy, T. S. Dharmarajan, and K. L. K. Paranjothi, "Derivatization of guar to various hydroxy alkyl derivatives and their characterization," Indian Drugs, vol. 43, no. 9, pp. 756-759, 2006.

[17] H. Gong, M. Liu, J. Chen, F. Han, C. Gao, and B. Zhang, "Synthesis and characterization of carboxymethyl guar gum and rheological properties of its solutions," Carbohydrate Polymers, vol. 88, no. 3, pp. 1015-1022, 2012. 

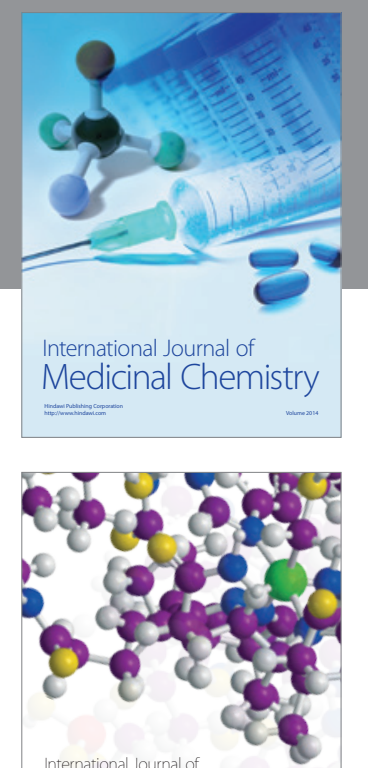

\section{Carbohydrate} Chemistry

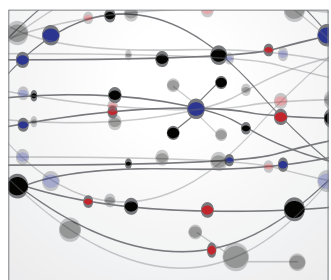

The Scientific World Journal
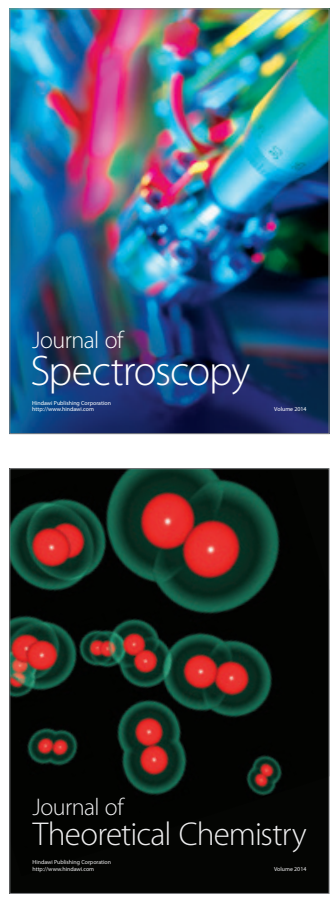
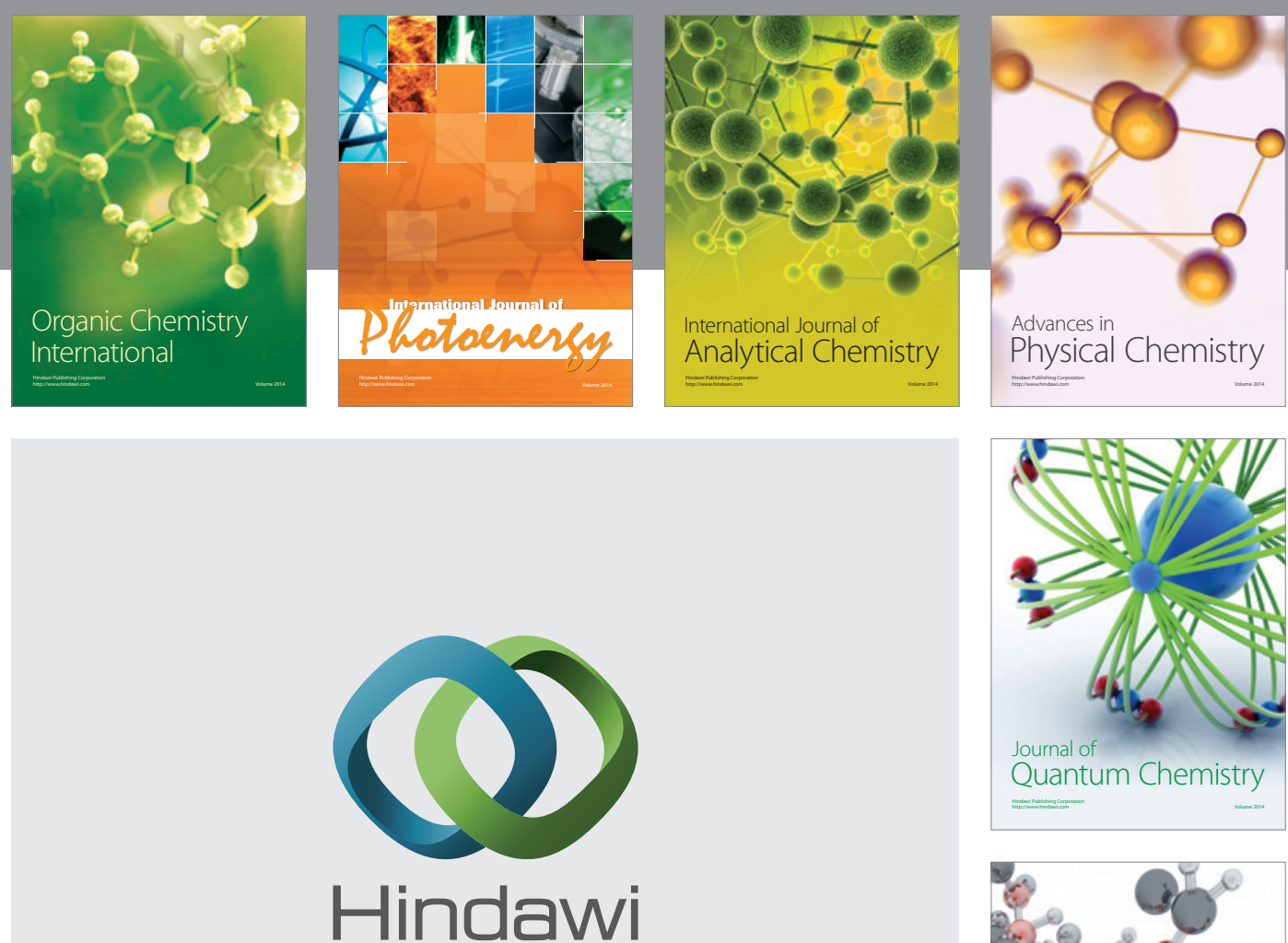

Submit your manuscripts at

http://www.hindawi.com

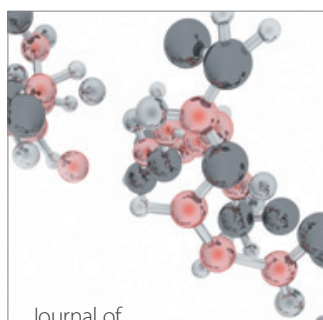

Analytical Methods

in Chemistry

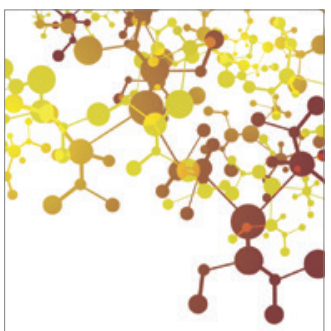

Journal of

Applied Chemistry

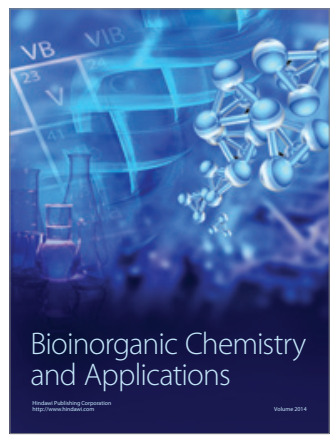

Inorganic Chemistry
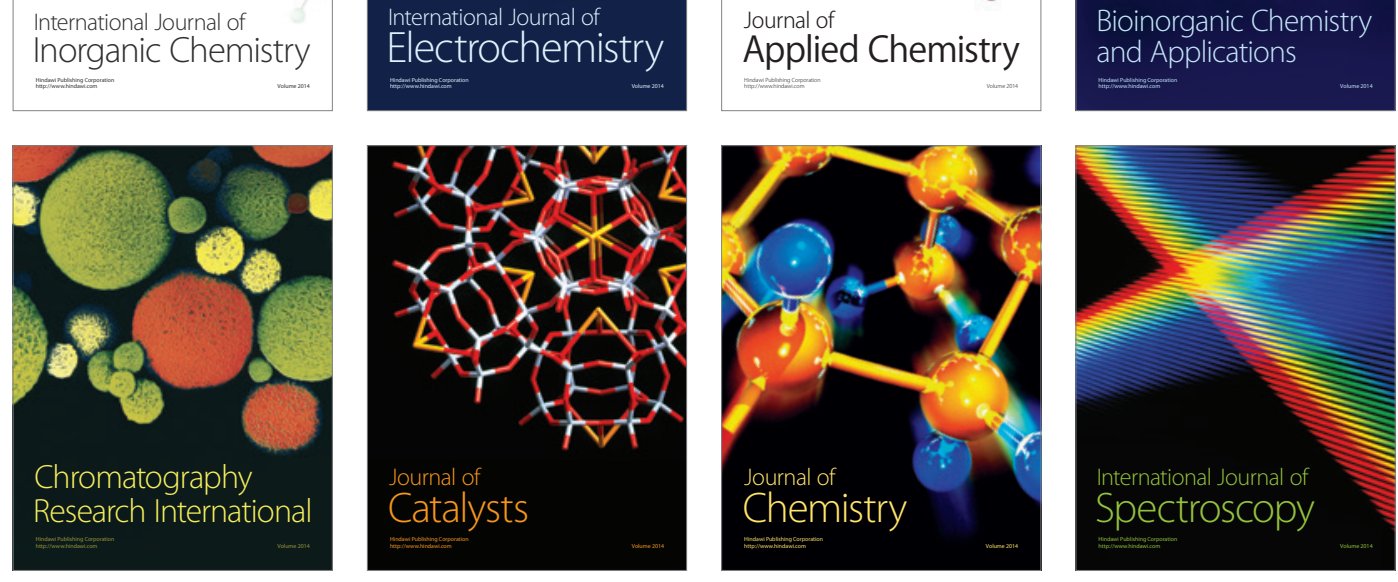